\title{
A Comparative Study of Learning Burnout of College Students
}

\author{
Yunjie Huang $^{1} \&$ Yi Zhang ${ }^{1}$ \\ ${ }^{1}$ School of Foreign Studies, Northwestern Polytechnical University, Xi'an, China \\ Correspondence: Yi Zhang, School of Foreign Studies, Northwestern Polytechnical University, Xi' an, China. Tel: \\ 86-130-9691-5179.
}

Received: October 14, 2020

Accepted: November 30, 2020

Online Published: December 7, 2020

doi:10.20849/aes.v5i2.831

URL: https://doi.org/10.20849/aes.v5i2.831

\begin{abstract}
Learning burnout circumstances appear commonly in the process of English learning. The current research investigates the features of learning burnout of English and a non-English major junior student from three dimensions, including exhaustion, cynicism and decreased professional self-efficacy. Results find that, firstly, these two groups of participants hold a similar degree of learning burnout, while non-English major participants show more individual variability of the learning burnout situation. Based on Krashen's Input hypothesis and Affective Filter hypothesis, there exist differences and similarities of reasons for participants' learning burnout. The high degree of learning burnout of these two groups is influenced by the choice of expected jobs as well as the sense of inferiority caused because of peer pressure. Furthermore, learning burnout of English major students is more influenced by teachers, having higher expectations for comprehensible and sufficient input. Therefore, teachers should pay attention to students' learning burnout situation and understand the specific needs and practical condition of junior students.
\end{abstract}

Keywords: learning burnout, krashen's hypothesis, EFL learners

\section{Introduction}

\subsection{Research Background}

English learning is a long and arduous activity. EFL learners may show burnout, apathy and low sense of self-efficacy in the process of learning English (Gao, 2012). Learning burnout (LB) refers to the negative attitude and behaviour of being tired of leaning due to learning pressure or lack of interest in learning (Lian, Yang \& Wu, 2006). Currently, college students' negative psychology towards study, showing fatigue, depression, confusion, lassitude, low sense of achievement and other emotional characteristics can all reflected by learning burnout (Chang \& Wu, 2016; Wan, Yu, Yan et al., 2020).

\subsection{Research Significance and Purpose}

Related studies mainly analysed the learning burnout of junior middle school students, senior high school students and college students from different dimensions (Jiang, Shao, el., 2018; Chen, Zhao, el., 2017; Chang \& Wu, 2016; Ana-Maira, 2015). Moreover, most of LB studies with the research focus of English learning merely concentrated on non-English major students (Gao, 2012). Then what are the characteristics of English learning burnout of English major students? Moreover, whether there exist the differences or similarities of the learning burnout circumstances between English and non-English major students are the question as well.

Considering the different English learning circumstance of English major and non-English major students, this study probes into the LB situation among these two groups of college students. Through carrying out a comparative study of the LB situation between English and non-English major students, this study aims to explore the similarities and difference between them and tries to provide a reasonable explanation based on Input hypothesis and Affective Filter hypothesis. Hopefully, this research can offer some specific help for English learning and teaching.

\subsection{Theoretical Framework}

Yang (2010) pointed out that EFL learners' LB is caused by the gap between the content, process or result of English learning activities and the anticipation of learners' in these aspects. It is a psychological syndrome mainly characterized by negative emotions related to depression, such as exhaustion, cynicism and decreased professional self-efficacy towards English learning. 
Krashen (1982) established the monitor theory, of which five hypotheses were put forward, including the acquisition-learning hypothesis, the natural order hypothesis, the monitor hypothesis, the input hypothesis and the affective filter hypothesis. Studies related to Krashen's theory covered diverse topics, including the application of hypotheses in teaching Chinese as a foreign language (Yang, 2004; Bai, 2009; Zhu, 2012), theoretical investigation (Wang, 2012) and discussion of the hypotheses (Yang \& Li, 2003; Zafar, 2011; Liu, 2015). In particular, due to the current epidemic situation, some studies focused on the influence factors of learning burnout in cloud-based teaching (Xiang \& Zhang, 2020; Wan, Yu, Yan et al., 2020). In the present study, Krashen's Input hypothesis and Affective Filter hypothesis is considered when delivering the explanation of the analysis of English LB situation.

\section{Methods}

\subsection{Research Questions}

In order to figure out the features of learning burnout situation of students from English and non-English majors, two main research questions are given and focused. For the first question, description of the learning burnout circumstances of students is presented through cultivating the numerical values of the burnout dimensions. Regarding the result of the calculation, the second step puts focus on the reasons under the consideration of the Affective Filter Hypothesis established by Krashen.

1. What are similarities and differences of LB situation between English and non-English major students?
A. What is the English LB situation among non-English major students?
B. What is the English LB situation among English major students?

2. How to explain the reasons of English LB situation based on the Krashen's hypotheses?

\subsection{Research Subjects}

30 English-major students and 30 non-English major students are selected as the research subjects. All of these 60 research subjects are junior students at Northwestern Polytechnical University. For the convenience of the recording procedure, all of these 60 students are coded.

Table 1. Description of research subjects

\begin{tabular}{lllll}
\hline & Number & Female $/ \%$ & Male $/ \%$ & Total \\
\hline English major students & 30 & 89.66 & 10.34 & \multirow{2}{*}{60} \\
\cline { 1 - 4 } Non-English major students & 30 & 21.21 & 78.79 & \\
\hline
\end{tabular}

They have just finished their third-year study and will begin the last year of their undergraduate study. For most of the students at this grade, it is essential and urgent for them to making decision about whether continuing the further study or finding jobs. Such kind of decision usually becomes the guidance of their attitude towards academic study including English study.

\subsection{Instruments and Research Design}

This research is a combination of quantitative and qualitative research, and self-report questionnaire and interview are two main strategies for analysing English LB circumstances.

(1) Instruments

As for the instruments employed in this research, Excel 16.28 and Numbers 6.1 are used to collect the data and analyse the results of the self-report questionnaire, including calculating mean and Std. Deviation. SPSS 13.0 and Python are employed to figure out the reliability value and to carry out the T-test of statistics. Later, Preview 10.1 is used to highlight and analyse the words of interviewee after the interview. 


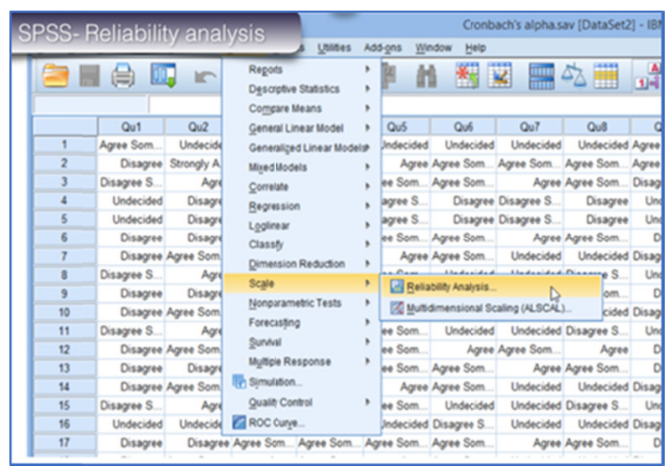

Figure 1. Example of the reliability analysis in SPSS 13.0

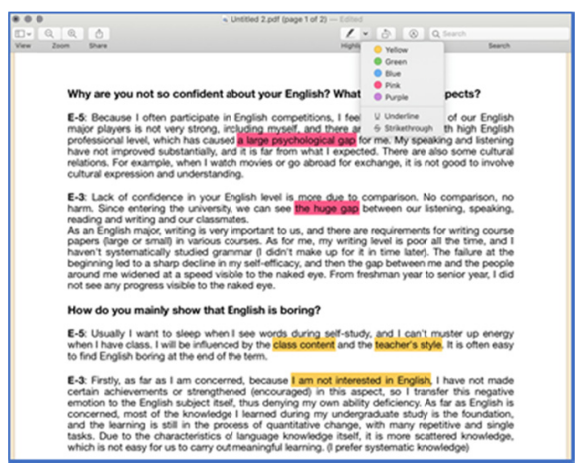

Figure 2. Example of Preview 10.1

(2) Self-report questionnaire

The modified foreign language learning burnout inventory (FLLBI) (Yang, 2010) and Maslach burnout inventory - student survey (MBI-SS) (Schaufeli, Martinez, el., 2002) are adapted for the introspection. Both of FLLBI and MBI-SS have three main dimensions of analysing LB circumstances, including exhaustion, cynicism, decreased professional self-efficacy.

\section{降低的自我效能感 \\ 13 我怀疑自己不能学好英语 \\ 14 英语听写的成绩差的让我对自己非常失望 \\ 15 英语语言课的学习让我快要崩溃了 \\ 16 真想干脆不学这些英语语言课算了 \\ 17 我会怀疑自己的英语发音到底是否准确}

$A B C D E F$

$A B C D E F$

$A B C D E F$

$A B C D E F$

$A B C D E F$

Figure 3. Sample of FLLBI (Adapted from Yang, 2012)

\begin{tabular}{|ll|}
\hline Exhaustion & \\
1 & I feel emotionally drained by my studies. \\
2 & I feel used up at the end of a day at university. \\
3 & I feel tried when I get up in the morning and I have to face another day at the university. \\
4 & Studying or attending a class is really a strian for me. \\
5 & I feel burned out from my studies. \\
\hline
\end{tabular}

Figure 4. Sample of MBI-SS (Adapted from Schaufeli, Martinez, el., 2002) 
Focusing on the comparison of above-mentioned approaches, MBI-SS provides a general view of learning burden investigation, while FLLBI is more concentrated on language learning. Nevertheless, it is still not enough when taking English major students into account in this research. Thus, a modified inventory is needed covering factors related to English major students.

As for the measurement and reliability, this study followed Maslach and Jackson's (1981) criteria. Following the lead of the Hassles Scale, each statement is rated on two dimensions: frequency and intensity. The frequency is labelled at each point and ranges from 1 to 6 . Meanwhile, the intensity scale ranges from 1 to 7 . The item format is listed below.

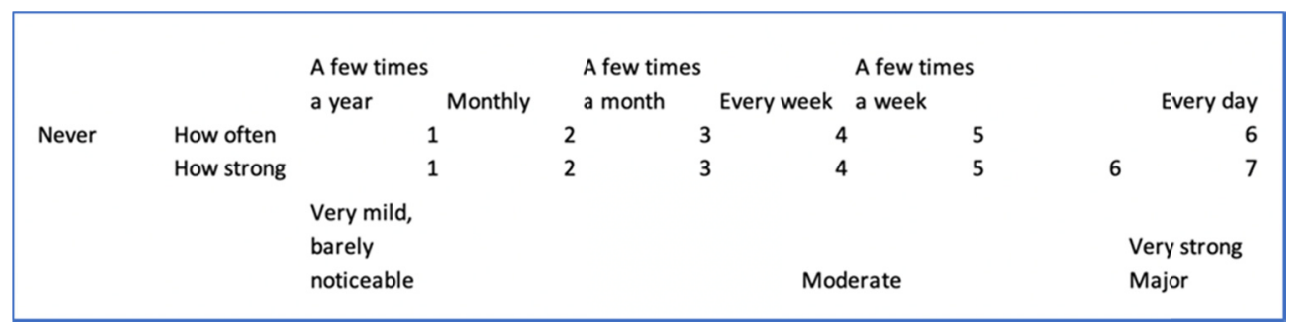

Figure 5. Criteria for labelling frequency and intensity (Adapted from Maslach \& Jackson, 1981)

Because this inventory is the combination of MBI-SS and FLLBI, of which the validity has been examined, in this paper merely the reliability of the questionnaire is tested. As Table 2 shows, Cronbach's $\alpha$ of each dimension is greater than 0.7 . Thus, this questionnaire has the high reliability.

Table 2. Reliability analysis of the questionnaire

\begin{tabular}{lcl}
\hline & Cronbach's Alpha & N of items \\
\hline Exhaustion & .823 & 5 \\
\hline Cynicism & .825 & 7 \\
\hline Decreased professional Self-efficacy & .783 & 6 \\
\hline
\end{tabular}

\section{(3) Interview}

The interview is carried out after analysing the self-report questionnaire. The author chooses 2 English major students and 2 non-English major students to take the interview with follow-up and thorough questions. The criteria for choosing these four interviewees are their numerical values of the inventory. Questions of the interview are supposed to be personalized to probe into the real features of four selected interviewees.

\section{Results and Discussion}

Results of the modified questionnaire finished by two groups have been presented and compared. Then, based on the answers of four interviewees, a thorough explanation of the possible reasons for LB situation is made.

\subsection{Results of English Learning Burnout Inventory}

(1) Non-English major students' LB situation

After imputing the data into a computer and scoring each item of three different dimensions, Excel and SPSS 13.0 were used to gain the mean and describe the obtained statistics. The descriptive statistical result of non-English major students' LB situation is shown below. According to Table 3, none of the three dimensions shows normal distribution. The skewness of exhaustion and decreased professional self-efficacy is higher than that of cynicism, which means that non-English major students' data distribution of exhaustion and decreased professional self-efficacy tend to be lower than cynicism. Meanwhile, kurtosis shows that decreased professional self-efficacy is the positive value, denoting that the data distribution presents high and narrow peak. While kurtosis of exhaustion and cynicism are negative values, distributing as low broad peaks. The statistics of all dimensions do not show a significant difference, ranging from 3.2875 to 4.6667. Besides, the minimums are from 1 to 1.5714 and the maximums are from 4.8571 to 5.6667 . 
Table 3. Three-dimensional descriptive statistics of non-English major students' LB

\begin{tabular}{llll}
\hline & Exhaustion & Cynicism & Decreased Professional Self-efficacy \\
\hline Mean & 2.8133 & 3.0809 & 2.8611 \\
\hline Median & 2.7 & 3.0714 & 3 \\
\hline Std. Deviation & 1.0644 & .9329 & 1.1061 \\
\hline Skewness & .3085 & .1895 & .3892 \\
\hline Kurtosis & -.2304 & -.9287 & .4348 \\
\hline Range & 4.2 & 3.2875 & 4.6667 \\
\hline Minimum & 1 & 1.5714 & 1 \\
\hline Maximum & 5.2 & 4.8571 & 5.6667 \\
\hline
\end{tabular}

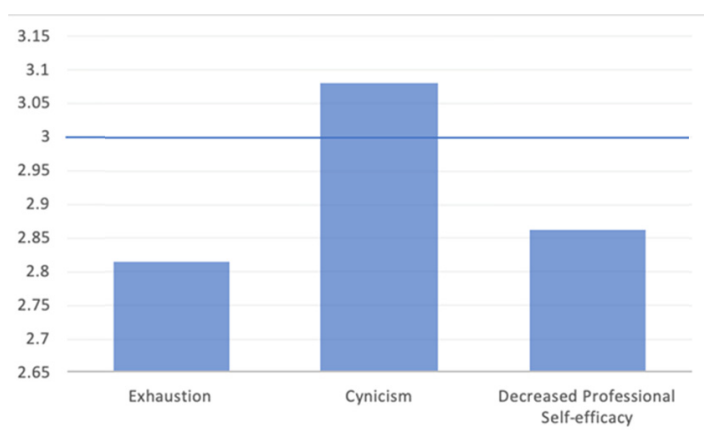

Figure 6. Three-dimension mean value of non-English major students' LB

From Figure 3, the mean value of cynicism is higher than that of exhaustion and decreased professional self-efficacy. Regarding 3 as the criteria for specifying a higher degree, merely cynicism is relatively high. Non-English major students' exhaustion and decreased professional self-efficacy are not high.

According to the above mean, skewness, kurtosis and extreme values, non-English major students' learning burnout situation can be interpreted as the following facets. Firstly, non-English students' degrees of exhaustion are not high $($ mean=2.8133<3). Although some participants' degrees of exhaustion are high (maximum=5.2>3), most of the participants' degrees are relatively low (skewness=0.3085). Secondly, participants have a higher degree of cynicism (mean $=3.0714>3>2.8133>2.8611$ ). Compared with another two dimensions, the data distribution of cynicism is relatively concentrated (kurtosis=-0.9287), implying that a high degree of cynicism is a common phenomenon among these 30 non-English major students. Thirdly, participants' situation of decreased professional self-efficacy is not so severe $($ mean $=2.8611<3$ ). However, this dimension has more significant individual difference than the additional two dimensions (kurtosis $=0.4348$ ).

(2) English major students' LB situation

The descriptive statistical result of English major students' LB circumstance is presented as follows.

Table 4. Three-dimensional descriptive statistics of English major students' LB

\begin{tabular}{llll}
\hline & Exhaustion & Cynicism & Decreased Professional Self-efficacy \\
\hline Mean & 2.5 & 3.1 & 2.4 \\
\hline Median & 2.4 & 3.1429 & 2.25 \\
\hline Std. Deviation & .7169 & .893 & .8878 \\
\hline Skewness & .5923 & .1487 & .4941 \\
\hline Kurtosis & -.431 & -.6987 & -.9298 \\
\hline Range & 2.8 & 3.4286 & 3.1667 \\
\hline Minimum & 1.4 & 1.5714 & 1 \\
\hline Maximum & 4.2 & 5 & 4.1667 \\
\hline
\end{tabular}




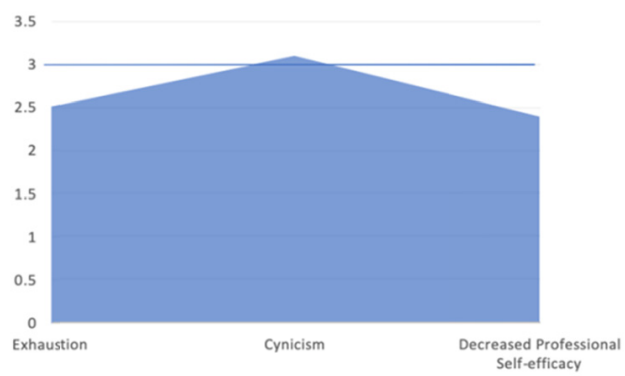

Figure 7. Three-dimension mean value of English major students' LB

From Table 4, data of three dimensions is not strictly distributed normally. Skewness shows that all three dimensions have positive values. Among these three dimensions, data distribution of cynicism tends to be the highest degree, followed by decreased professional self-efficacy and the lowest degree is exhaustion. Kurtosis shows that data of these three dimensions presents the low broad peaks. The statistics of all dimensions do not show a significant difference, ranging from 2.8 to 3.4286. Additionally, the minimums are from 1 to 1.5714 and the maximums are from 4.1667 to 5 . Based on Figure 4, the score of cynicism is higher than 3, indicating that, for English major students, the degree of cynicism is stronger than exhaustion and decreased professional self-efficacy.

To sum up the LB circumstances, explanation of the data of these three dimensions is listed below. Firstly, English major students' degrees of exhaustion are not high (mean $=2.5<3$ ), although some participants hold the strong exhaustion (maximum $=4.2>3$ ), even compared with another two dimensions, most of the English major participants have the lower level of exhaustion (skewness $=0.5923>0.4941>0.1487$ ). Then, with regard to cynicism, its degree is most serious (mean=3.1>3>2.5>2.4). Based on the skewness $(0.1487)$ and kurtosis $(-0.6987)$ of cynicism, data finds that participants with a lower degree of cynicism and participants with a higher degree of cynicism hold a similar proportion. Thirdly, the level of decreased professional self-efficacy is relatively lowest (mean $=2.4<2.5<3<3.1$ ). Moreover, the difference of scores of this dimension is smaller than exhaustion and cynicism (kurtosis $=-0.9298<-0.6987<-0.431$ ).

\subsection{Similarities and Difference of the LB Situation Between the Two Groups}

For the sake of figuring out the similarities or difference of the LB situation between non-English and English major students, the data has been processed by using the graph for specific comparison.

Table 5. Comparison of the mean value of three dimensions

\begin{tabular}{llllll}
\hline & \multicolumn{2}{l}{ Number } & Mean & & $P$ value \\
\hline Total & NES & ES & NES & ES & \\
\hline Exhaustion & 30 & 30 & 2.9184 & 2.67 & \\
\hline Cynicism & 30 & 30 & 2.8133 & 2.5 & .113 \\
\hline Decreased Professional Self-efficacy & 30 & 30 & $\mathbf{3 . 0 8 0 9}$ & $\mathbf{3 . 1}$ & .819 \\
\hline
\end{tabular}

Note: NES for non-English major students; NES for English major students; $\mathrm{p}<0.05$ means the difference is significant

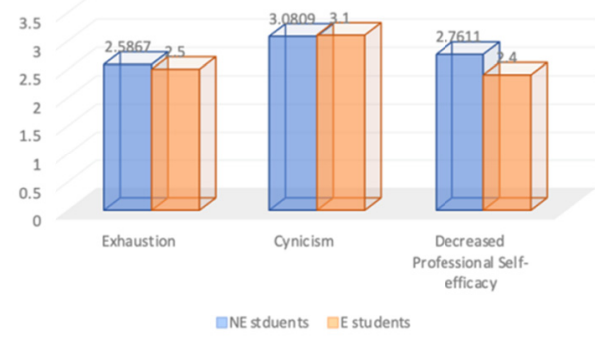

Figure 8. Comparison of the three-dimensional descriptive statistics of two groups 
From Table 5 and Figure 8, both of English and non-English major students have the highest degrees of cynicism, of which the values are higher than the criterial $(3<\mathrm{NES}=3.0809<\mathrm{ES}=3.1)$. Compared with cynicism, additional two dimensions are not severe. Although there does not exist a significant difference between these two groups $(p=0.113>0.05 ; p=0.819>0.05 ; p=0.743>0.05)$, English major students' degrees of exhaustion and decreased professional self-efficacy are higher than that of non-English major students. However, the circumstance that English major students hold the higher degrees of cynicism does not tally with the author's expectation.

In order to distinguish the feature of data distribution between these two groups, variance and std.deviation are calculated and compared. From Table 6 and Figure 9-11, the data of English major students fluctuated less than that of non-English major students. This result shows that the data of non-English major participants exists greater individual variability.

Table 6. Comparison of the variance and std. deviation of three dimensions

\begin{tabular}{lllll}
\hline & Variance & \multicolumn{2}{l}{ Std. Deviation } \\
\hline Total & NES & ES & NES & ES \\
\hline Exhaustion & .9668 & .8326 & 1.0344 & .8326 \\
\hline Cynicism & .966 & .717 & 1.0644 & .7169 \\
\hline Decreased Professional Self-efficacy & .9329 & .893 & .9329 & .893 \\
\hline
\end{tabular}

Note: NES for non-English major students; NES for English major students

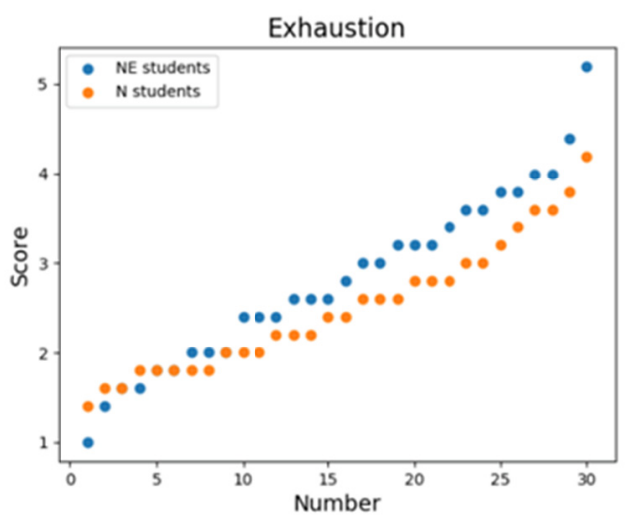

Figure 9. Comparison of data distribution - exhaustion

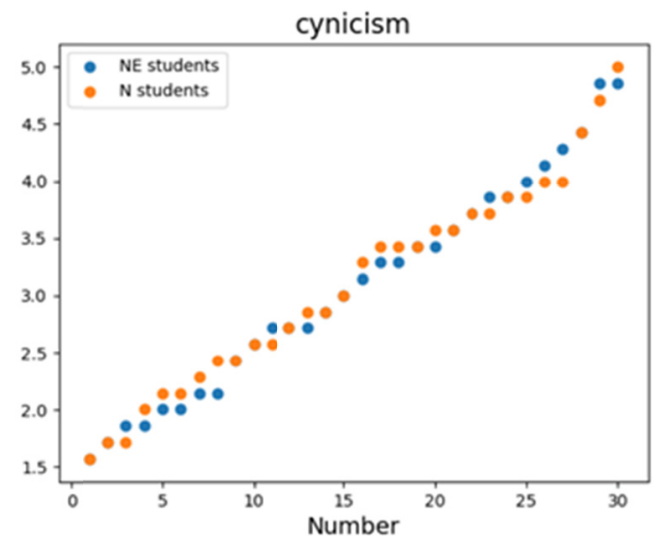

Figure 10. Comparison of data distribution - cynicism 


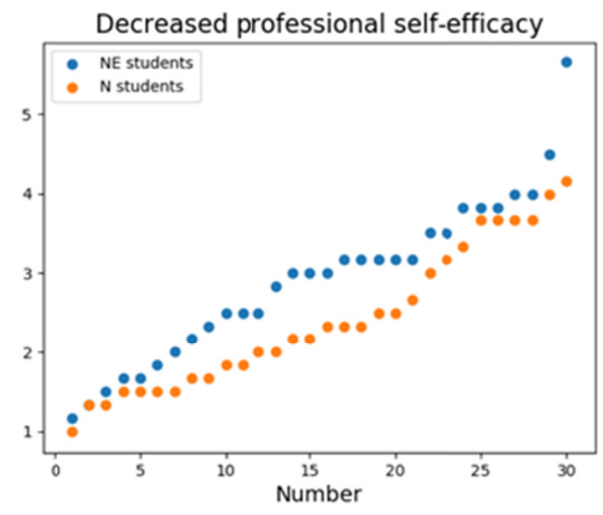

Figure 11. Comparison of data distribution - decreased professional efficacy

Due to the calculated result of three dimensions, cynicism is the most severe situation between the two groups of participants. Thus, the follow-up questions of the interview are mainly related to cynicism. Taking the difference of the individual variability between two groups into consideration, interviewees to be selected are distinct. Regarding non-English major participants, of whom the individual difference is more prominent, one participant with a higher value of cynicism and one with the average degree of cynicism are to be chosen as interviewees. While for English major students, two participants with a relatively high degree of cynicism are to be selected as interviewees.

\subsection{Explanation of the Reasons From the Perspective of Krashen's Hypotheses}

Based on the answers of four selected interviewees, reasons for English and non-English major students' LB situation are explained separately. Reasons for interviewees' LB circumstance can be classified from two perspectives, of which one is the Input hypothesis and another one is the Affective filter hypothesis. For the convenience of addressing the interviewees, they are referred to as NES-1, NES-2 and ES-1, ES-2. (NES for non-English major student; ES for English major student)

(1) Reasons for non-English major students' learning burnout situation

Limited English proficiency as well as the choice of time and energy is the main facet that influences the non-English major students' LB circumstances. Concerning English proficiency, most of the participants are students of engineering and science. Their original English proficiency, especially oral English proficiency, is not so good as those who major in arts.

NES-1: "I don't think English test score is the most important thing, instead, oral English is the most necessary skill that I need. However, I'm not good at both speaking and listening. Moreover, I feel that I am not suitable for learning English and even if I spend a lot of time learning English, I still do not improve."

NES-2: "The most important reason for feeling unconfident is to compare with my peers. When I communicate with my peers, I find that some of them are really do well in English listening and speaking, which I lack and expect."

Feeling not good at learning English or speaking out, non-English major students are more likely to be unconfident, which is the main reason for creating a high affective filter. Besides, after compared with peers with excellent English proficiency, the interviewee's psychological gap also leads to the feeling of English inferiority.

Another cause of the high affective filter is the participants' own choice of time and energy. Since they need to pay many efforts in their own professional field, they regularly make some choice of time and energy when learning English.

NES-1: "The time and energy I spent in learning English cannot give me enough feedback like what I've done in my own major. Furthermore, if I spend a lot of time learning English, I do not have sufficient time and energy to improve my professional skill, which is the passport for me to find a good job."

NES-2: "My English listening skill is the extremely huge barrier in my TOEFL test, I find that I can't get good grades no matter how hard I practice, and then I have no patience." 
English skill for these non-English major students is merely a tool to make them even better and more competitive. There is not enough motivation for them to spend too much time and energy on English learning. It is easy for non-English major students to lose patience if they cannot see improvement quickly.

Non-English major students, more or less, pay more attention to themselves. Compared with interviewees' affective filters, teachers mentioned in their words do not have much influence on their English learning.

(2) Reasons for English major students' learning burnout situation

For English major interviewees, psychological gap and self-confusion cause the high affective filter. First of all, such kind of psychological gap exists between the ES and their peers.

ES-1: "I often participate in English competitions, and I feel that English competitiveness of our English major students, including myself, is not strong. There are many non-English major students with quite high English professional level, which has caused a large psychological gap."

ES-2: "Lack of confidence in my English learning is more or less due to comparison. No comparison, no harm. Since entering our university, I can see the huge gap in English listening, speaking reading and writing between me and my classmates. Moreover, so-called gap between me and my peers is widening at a rate visible to the naked eyes."

According to the answer of ES-1, general circumstances that English major students cannot gain the advantage in English contest make him have a huge psychological gap, which leads to the high affective filter. ES-2's high filter comes from the comparison between herself and her classmates. Such a gap exists at the beginning of her undergraduate time and is continuously widening. Gradually her filter becomes higher. Furthermore, both of ES-1 and ES-2 mentioned that they "cannot see the visible improvement of their English talent after undergraduate study." They are not confident in their English learning because they are not moving forward in the process of English study. Thus, lack of self-confidence and a huge psychological gap make them hold the high affective filter.

In terms of self-confusion, both of two English major interviewees speak candidly that a period time of self-confusion make them lose the direction of English learning and also reduce some enthusiasm studying English. The lack of enthusiasm leads to learner' high affective filter.

ES-1: "Usually, I like to try new things in English learning. However, I want to be stable in my junior year. I do not want to push myself very hard for I feel a little confused in the direction of my future, choosing whether to continue the postgraduate study, finding jobs or studying abroad."

ES-2: "There is a lack of clear learning plan in my freshmen year, and I know little about it. Therefore, my English learning is always at a standstill."

Based on the answers, the most explicable reason for interviewees' self-confusion and the high affective filter is that students are at a critical stage in planning their lives after their undergraduate years. They have more things to take into consideration, consuming their energy and distracting them from learning English passionately.

The second main facet is that unreasonable course design and monotonous teaching lead to the incomprehensible and insufficient input.

ES-1: "I think our course design has a problem; a lot of things are quite vague. Some core courses always open late and we have limited time to apply what we have learnt. Besides, some teachers have no practical content in their lessons. There is an obvious limit to what we can learn."

ES-2: "With a weak foundation, it is difficult to establish the connection between the new and old knowledge I have learnt in class. Some tasks delivered by teachers may be beyond my competence. Teachers may also have difficulty grasping the needs of different students in a classroom."

Interviewees' words show that they have, to some extent, the displeasure towards the course design and teaching. Unreasonable course design as well as vague and general teaching content brings about the incomprehensible and insufficient input. Besides, the lack of needs analysis before and after the course also decreased the degree of accepting the input.

\section{Conclusion and Recommendations}

Through the investigation of difference and similarities of English learning burnout circumstances between English and non-English major students, this research finds that English and non-English major students hold the similar degree of English LB, which does not tally with the author's expectation. Regarding statistics of three dimensions of LB, English major participants do not have the obvious individual variability, while non-English major students are quite different from one to another. Since the selected participants are limited to junior students, 
the results obtained in the follow-up interview have certain particularity. Both of these two groups feel unconfident because of comparing with their peers. The psychological gap caused by the gap with peers is the foremost reason for high affective filter. Meanwhile, English and non-English major students concentrate on their own plans for the future. The expectation of careers affects how much importance they attach to English learning. Less attention leads to high affective filter as well. Nevertheless, there still exists a difference between the two groups. Compared with non-English major participants, English major participants have a relatively higher requirement for their teachers and instructor. They are more looking forward to comprehensible and sufficient input from teachers.

Based on this research, it is worth reflecting on the English LB circumstances of junior students. For students they, understanding the importance and necessity of English is essential, no matter for English or non-English major students. On the other hand, it is supposed that teachers should pay attention to students' need as well.

\section{Acknowledgments}

This paper was sponsored by the Seed Foundation of Innovation and Creation for Graduate Students in Northwestern Polytechnical University CX 2020033.

\section{References}

Bai, Y. (2009). Krashen's theory of "input hypothesis" and "affective filter hypothesis" and college public foreign language listening and speaking teaching. Journal of Capital University of Economics and Business, 11(06), 122-125.

Cazan, A.-M. (2015). Learning motivation, engagement and burnout among university students. Procedia Social and Behavioral Sciences, 187(13), 413-417. https://doi.org/10.1016/j.sbspro.2015.03.077

Chang, J., \& Wu, D. (2016). Study on college students' learning burnout based on grounded theory -- a case study of X university. Exploration of Higher Education, (08), 62-65.

Chen, W., et al.. (2017). Study on the establishment and reliability and validity of learning burnout scale for high school students -- based on the analysis of CTT, GT and IRT. Journal of Southwest University (Social Science Edition), 43(04), 112-119.

Gao, G. (2012). An analysis on the characteristics of non-major' foreign language learning burnout (pp. 113-118).

Wan, H. Y., Yu, J. Q., Yan, N. J., \& Huang, J. H. (2020). Relationships between learning burnout and internet addiction among undergraduates during the novel coronavirus pneumonia: mediating effect of career adaptability. China Journal of Health Psychology.

Jiang, Y., et al.. (2018). The relationship between group attachment, self-compassion and learning burnout in the class of junior high school students. Psychological Development and Education, 34(04), 472-480.

Krashen, S. (1982). Principles and practice in second language acquisition. New York: Pergamon Press.

Lian, R., et al.. (2006). The status and relationship of college students' professional commitment and learning burnout. Psychological Science, (1), 47.

Liu, D. (2015). A critical review of Krashen's input hypothesis: three major arguments. Journal of Education and Human Development, 4(4), 139-146.

Maslach, C., \& Jackson, S. E. (1981). The Measurement of Experienced Burnout. Journal of Occupational Behaviour. https://doi.org/10.1002/job.4030020205

Schaufeli, W. B., \& Martinez, I. (2002). Burnout and engagement in university students: a cross-national study. Journal of Cross-Cultural Psychology, (33). https://doi.org/10.1177/0022022102033005003

Wang, C. (2012). Construction of college English acquisition model -- from the perspective of krashen's theory. Social Science Front, (10), 271-272.

Wei, X., \& Ping, Z. (2020). Influence Factors of study burnout of nursing students in cloud-based teaching. Journal of Nursing, 27(20), 7-11.

Yang, R. (2004). The role of input and affective filtering in college English teaching. Journal of Central South University for Nationalities (Humanities and Social Sciences), 247-249.

Yang, T. (2010). A study on the relationship between foreign language burnout and motivation. Southwest University.

Yang, W., \& Li, T. (2003). Research on monitoring model of second language acquisition. Educational 
Exploration, (06), 76-77.

Zafar, M. (2011). Monitoring the 'monitor': a critique of Krashen's five hypothesis. Dhaka University Journal of Linguistics, 2(4), 139-146. https://doi.org/10.3329/dujl.v2i4.6903

Zhu, W. (2012). Krashen's "input hypothesis" theory in teaching Chinese as a foreign language. Hubei Social Sciences, (06), 139-142.

\section{Copyrights}

Copyright for this article is retained by the author(s), with first publication rights granted to the journal.

This is an open-access article distributed under the terms and conditions of the Creative Commons Attribution license (http://creativecommons.org/licenses/by/4.0/). 